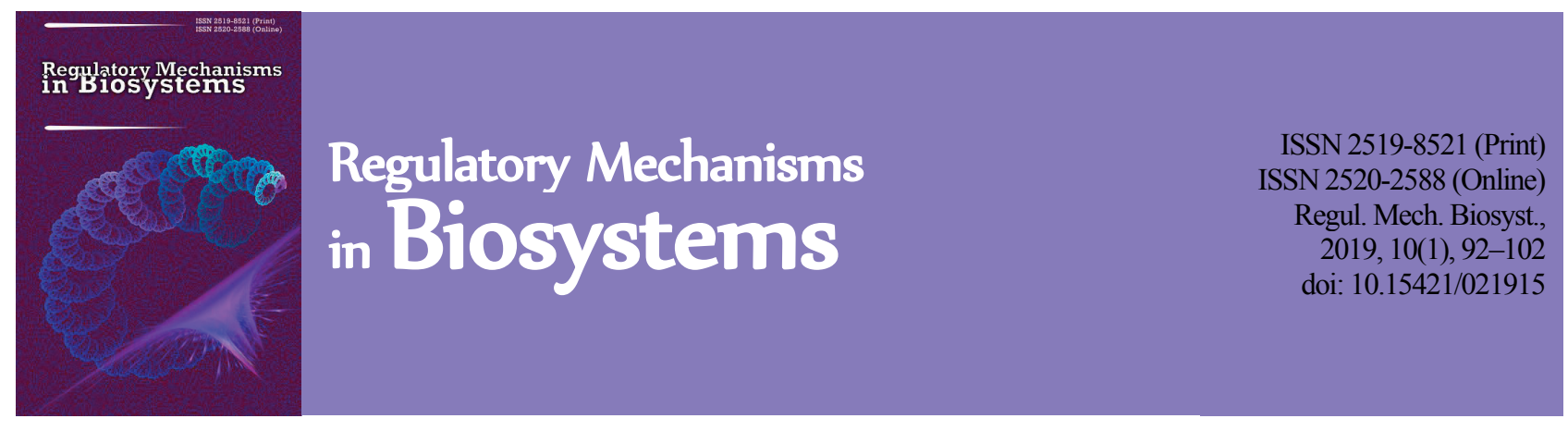

\title{
Mathematical interpretation of artificial ovoids and avian egg shapes (part I)
}

\author{
I. S. Mytiai*, A. V. Matsyura** \\ *National University of Life and Environmental Science of Ukraine, Kyiv, Ukraine \\ **Altai State University, Barnaul, Russian Federation
}

Article info

Received 10.01.2019

Received in revised form 14.02.2019

Accepted 18.02.2019

National University of Life and Environmental Science of Ukraine, General

Rodimtsev st., 19, building 1, Kyiv, 03041, Ukraine. E-mail:oomit99@ukr.net

Altai State University Lenin ave., 61, Barnaul, 656039, Russian Federation Tel.: +7-3852-291-291 E-mail:

amatsyura@gmail.com

\section{Mytiai, I. S., \& Matsyura, A. V. (2019). Mathematical interpretation of artificial ovoids and avian egg shapes (part I). Regulatory Mechanisms in Biosystems, 10(1), 92-102. doi:10.15421/021915}

We performed comparative analysis of curvature characteristics of bird eggs and used ovoid profiles from various authors, our own geometric profiles, and archive bird egg profiles from our database. We suggested that the possible ovoids arise by changing the curvature radii of the polar and lateral zones. We compared the constructed curves and curves presented in oological literature with the pictures of the real bird egg profiles. The volume of actual material includes 16,490 eggs from 800 species of 20 bird orders. Specially designed computer software had calculated the radius of curvature of real bird eggs from photos and drew out the halfprofiles presented in our article. We supposed that the asymmetrical ovoid is the most widespread geometric egg-shaped figure, which can easily be obtained by combination of circles. We also calculated that if the ovoid diameter were taken as a unit, then the radius obtuse (infundibular) pole would be equal to its half-length, lateral (side arcs) is equal two lengths, and the cloacal arch is $1-\sqrt{2} / 2$. From this suggestion, we concluded that the length of the ovoid is $2-\sqrt{2} / 2$ and its cloacal radius is equal to the difference between the length of ovoid and its diameter $\left(\mathrm{r}_{\mathrm{c}}=\mathrm{L}-\mathrm{D}\right)$. We analyzed the geometry of this asymmetrical oval and came to the conclusion that this is the basic form able to generate the derivative forms. We discovered that the centres of the arcs which form it lie on one basic/supporting circle, the diameter of which is equal to the ovoid diameter. All other ovoids, which have radius equal to radius of the infundibular zone we called the real ovoids. The changes in the radii of the lateral arcs are caused by the movement of their centres along a horizontal line passing through the centre of the base circle. This causes the prolongation or shortening of the ovoids. Sizes of cloacal arcs depended on the lateral, and their centres are placed along the vertical axis. Variability of the sizes of the abovementioned arcs caused the variability of form of the bird eggs. For their classification, we have proposed to divide them into five groups: sphere-like, circle, obtuse, droplet, and cone-shaped. Further, we separated some more groups: short, shortened, normal, lengthened, and long; according to the sizes of cloacal arcs - large radius, middle radius, and small radius ovoids. As a result, we have 80 forms of real ovoids - standards which describe the varieties of bird eggs. Each of them has its own number, name, geometrical figure, polynomic equation, and correlations of ovoid parameters. This set of ovoids is sufficient to describe the specifics of any form of bird eggs.

Keywords: bird eggs; curvature; ovoid; variability of the sizes; egg shape.

\section{Introduction}

The egg is a unique natural phenomenon, which is closely related to different aspects of human life. It is a food product, research object of ornithology and poultry breeding, and an object of leisure. Egg-shaped curves attract special attention in mathematics, art, architecture, philosophy, and religion. Information about aspects of eggs is presented in a great variety of literature sources. In historical aspect, egg-shaped profiles are known from time of the Ancient Persians, Byzantium, and the Kievan Rus (Ghyka, 1979). These sketches were used for building the domes of the temples. Later, egg-shaped profiles were intensively used in architecture, manufacture, painting, and applied art.

In the Renaissance, ovoid curves were mentioned in works of Albrecht Durer (1471-1528), Johannes Kepler (1571-1630), Galileo Galilei (1564-1642), Rene Descartes (1596-1650), Giovanni Cassini (1625-1712), Isaac Newton (1643-1727), and Maxwell James Clerk (1831-1879). In the XIX and XX centuries, studies of curves were intensively continued, resulting in a number of research papers. Some of these publications were dedicated to obtaing egg-shaped curves by combination and smooth changeover of circles arcs with different diameter (Erchart, 1957; Nishiyama, 1986; Dixon, 1987).

Rosin (2004), Iwamoto (2006), and Cuadrado (2010) further developed this suggestion. Hreinsdóttir (2010), Obradović (2010), Zarrao- nandia (2013), and Caravaca (2015) presented some mathematical elaborations of this theory. Nevertheless, a significant part of the publications was devoted to convex curves, which were received with the help of algebraic equations (Köller, 2000; Ferréol, 2016; Yamamoto, 2017). All above-mentioned researches were not related to research into real eggs and were mathematical searches of different egg-shaped algebraic curves. Description of real eggs by mathematical methods began in the second part of the past century. In scientific literature, there are many methods of constructing ovoid profile with the above-mentioned perspectives of using them in oology (Preston, 1953, 1968; Paganelli et al., 1974; Anderson, 1978). Errős (1983), Todd \& Smart (1984), and Myand (1988) published similar ideas. Later et al. (1997), Hutchinson (2000), Mattas (2001), and Narushin (2001) improved these ideas. Johnson et al. (2001), Führer-Nagy (2002), and Baker (2002) also made a significant contribution. Since the development of specific software, these ideas have been presented in Heck (2004), Bridge (2007), and Mytiai (2008). In the beginning of this century, egg curvature patterns remained as objects of discussion (Möller, 2009; Francevich, 2010; Nishiyama, 2010). Some authors tried to concentrate on limited species (Murray et al., 2013; Avila, 2014; Mieszkalski, 2014), while others present the results obtained from a large number of species (Deeming \& Ruta, 2014; Nedomová \& Buchar, 2014; Stoddard etal., 2017). The method of photographic analysis was elaborated and presented in Mytiai \& Matsyura (2017, 2018), Deeming (2018), and 
Biggins et al. (2018). Proceeding from the above, we were interested how similar the egg-shaped curves constructed by mathematicians, architects and builders are to the profiles of real bird eggs.

\section{Material and methods}

We used ovoid profiles from various authors (Dixon, 1987; Köller, 2000; Iwamoto, 2006). We used the results of Nishiyama (2012), Mieszkalski (2014), Yamamoto, (2017) for comparative analysis together with our own geometric measurements and profiles from our database. To develop the geometric system of ovoid profiles, we used the figure of the Pythagorean "fish bubble" Vesica piscis. This figure is formed by the intersection of two circles with the same radius, imposed so that the edge of one circle passes through the center of another (Fig. 1a). Robert Dixonin in his "Mathographics" (1987) describes a technique for joining circular arcs that was typical for the XV century artist Albrecht Durer. Durer used this technique to design the alphabet for the printing press. The main idea used in Durer's technique of joining arcs of different radii is that the join will be smooth (i.e. the tangent lines will line up) if a straight line drawn through the centres of the two arcs passes through the point where they join. We concluded that we can obtain the coordinates of Descartes, Riemann, and Mobius by dividing the circles; moreover, we deal here with all geometric figures (Mityay et al., 2003), including the system of ovoids (Mityay \& Matsyura, 2017). If we draw the circles in the centre of a figure and two circles in its opposite edges, which are combined with the circles surrounding them, then we get an oval. If only one circle is constructed on the periphery, we obtain an ovoid profile (marked bold in Fig. 1b). All ovoid parameters are shown in Figure 1d. Theoretically, the possible ovoids arise by changing the curvature radii of the polar and lateral zones (the direction of change is indicated by arrows).

The curves constructed by us and the curves of the abovementioned authors were compared with photos of real bird egg profiles. The volume of actual material includes 16,490 eggs from 800 species of 20 bird orders (Table 1).Specially written computer software calculated the radius of curvature of real bird eggs from their pictures and drew out the half-profiles (Fig. 2).
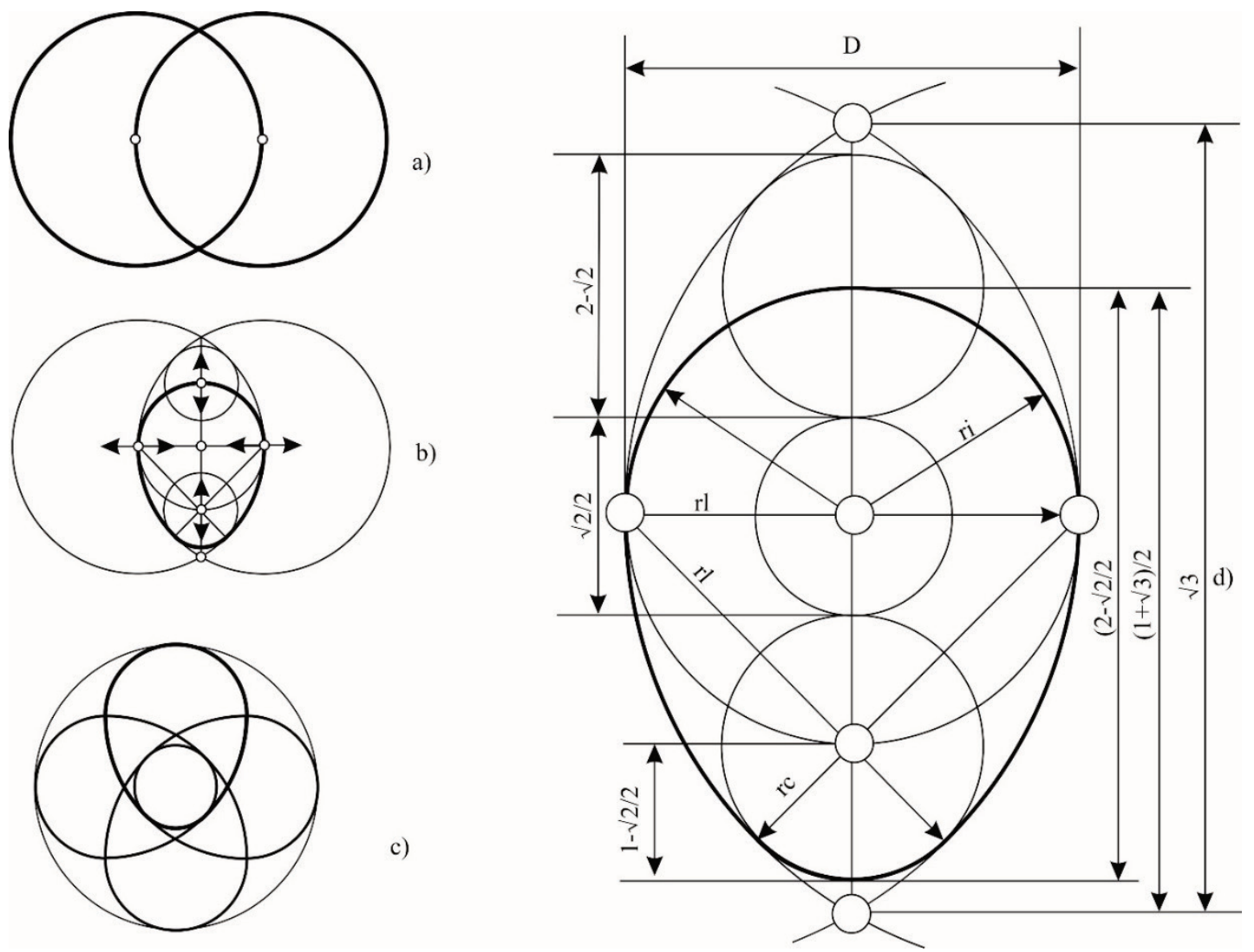

Fig. 1. Construction methods and parameters of the basic egg-shaped profiles: $a$-Vesica piscis; $b$ - the matrix of all forms of eggs; $c$-construction of the basic egg-shaped profile and combination of circles; $d$ - the basic egg-shaped profile and its parameters

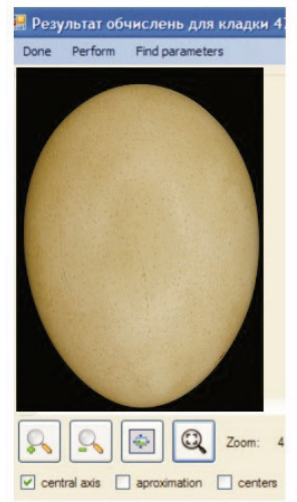

\begin{tabular}{|l|l|}
\hline r1 (Ic) & 0,329 \\
\hline r2 (Il) & 0,853 \\
\hline r3 (Ii) & 0,441 \\
\hline Squar & 3,907 \\
\hline Volum & 0,707 \\
\hline Iel & 1,372 \\
\hline Icomp & 1,175 \\
\hline
\end{tabular}
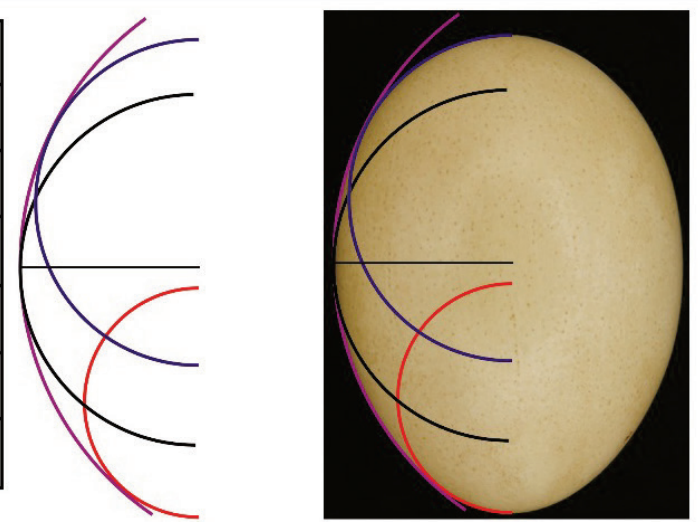

Fig. 2. Screenshots results of computer processing of egg pictures: r1(Ic) - radius (index) of cloacal zone;

r1(Il) - radius (index) of lateral zone; ri(Ii) - radius (index) of infundibular zone; Iel - elongation index; Icomp - index of complementarity 
Table 1

Raw data

\begin{tabular}{|c|c|c|c|c|}
\hline \multirow{2}{*}{ No } & \multirow{2}{*}{ Orders } & \multicolumn{3}{|c|}{ Quantity } \\
\hline & & species & clutch & eggs \\
\hline 1 & Anseriformes & 48 & 1,024 & 1,415 \\
\hline 2 & Apodiformes & 4 & 14 & 39 \\
\hline 3 & Caprimulgiformes & 14 & 46 & 61 \\
\hline 4 & Charadriiformes & 111 & 1,201 & 2,121 \\
\hline 5 & Ciconiiformes & 14 & 492 & 821 \\
\hline 6 & Columbiformes & 21 & 111 & 176 \\
\hline 7 & Coraciiformes & 5 & 59 & 250 \\
\hline 8 & Cuculiformes & 10 & 84 & 84 \\
\hline 9 & Falconiformes & 47 & 1,584 & 2,315 \\
\hline 10 & Galliformes & 26 & 114 & 446 \\
\hline 11 & Gaviiformes & 5 & 169 & 233 \\
\hline 12 & Gruiformes & 24 & 215 & 601 \\
\hline 13 & Passeriformes & 290 & 2,675 & 5,600 \\
\hline 14 & Pelecaniformes & 10 & 122 & 256 \\
\hline 15 & Piciformes & 11 & 180 & 949 \\
\hline 16 & Podicipediformes & 7 & 265 & 510 \\
\hline 17 & Procellariiformes & 7 & 117 & 117 \\
\hline 18 & Sphenisciformes & 5 & 29 & 39 \\
\hline 19 & Strigiformes & 17 & 92 & 271 \\
\hline \multirow[t]{2}{*}{20} & Struthioniformes & 4 & 39 & 41 \\
\hline & Total & 681 & 8,663 & 16,490 \\
\hline
\end{tabular}

Table 2

Groups of ovoids

\begin{tabular}{lrr}
\hline \multicolumn{1}{c}{ Group of ovoids } & $\mathrm{n}$ & \multicolumn{1}{c}{$\%$} \\
\hline Real ovoids & 3,491 & 21.19 \\
Symmetric pseudo-ovoids & 175 & 1.10 \\
Asymmetric pseudo-ovoids & 12,814 & 77.71 \\
\hline
\end{tabular}

The naming of egg zones is based on Kostin (1977); the name of egg forms was presented according to the standards developed by Mytiai \& Matsyura (2017) and divided into three groups (Table 2). This report analyzes only real ovoids, which were $21.2 \%$ from the total $(n=16,490)$.

\section{Results}

The asymmetrical ovoid is the most widespread geometric eggshaped figure, which can be easily obtained by combination of circles. If we consider the ovoid diameter as a unit, then radius obtuse (infundibular) pole is equal to its half length, lateral (side arcs) is equal to two lengths, and the cloacal arch is $1-\sqrt{2} / 2$.

So, the length of the ovoid is $2-\sqrt{2} / 2$ and its cloacal radius is the difference between length of the ovoid and its diameter: $\mathrm{rc}=\mathrm{L}-\mathrm{D}$. We have analysed the geometry of this asymmetrical oval and come to conclusion that it can be the basic form, from which the others could be generated. We discovered that centres of the arcs which form it lie on one basic/ supporting circle, the diameter of which is equal to void diameter. All other ovoids which have radius equal to radius of the infundibular zone we called the real ovoids. The changes in the radii of the lateral arcs are caused by the movement of their centres along a horizontal line passing through the center of the base circle. This causes the prolongation or shortening of the ovoids. Sizes of cloacal arcs depended on the lateral arcs, and their centres are placed along the vertical axis. Variability of arc sizes caused the variability of form of bird eggs. We proposed to divide them into five groups: sphere-like, circle, obtuse, droplet and cone-shaped (Mytiai \& Matsyura, 2017). We presented the directions of changes in the radii of lateral and cloacal arcs and the average configuration of these figures in Figure 3.
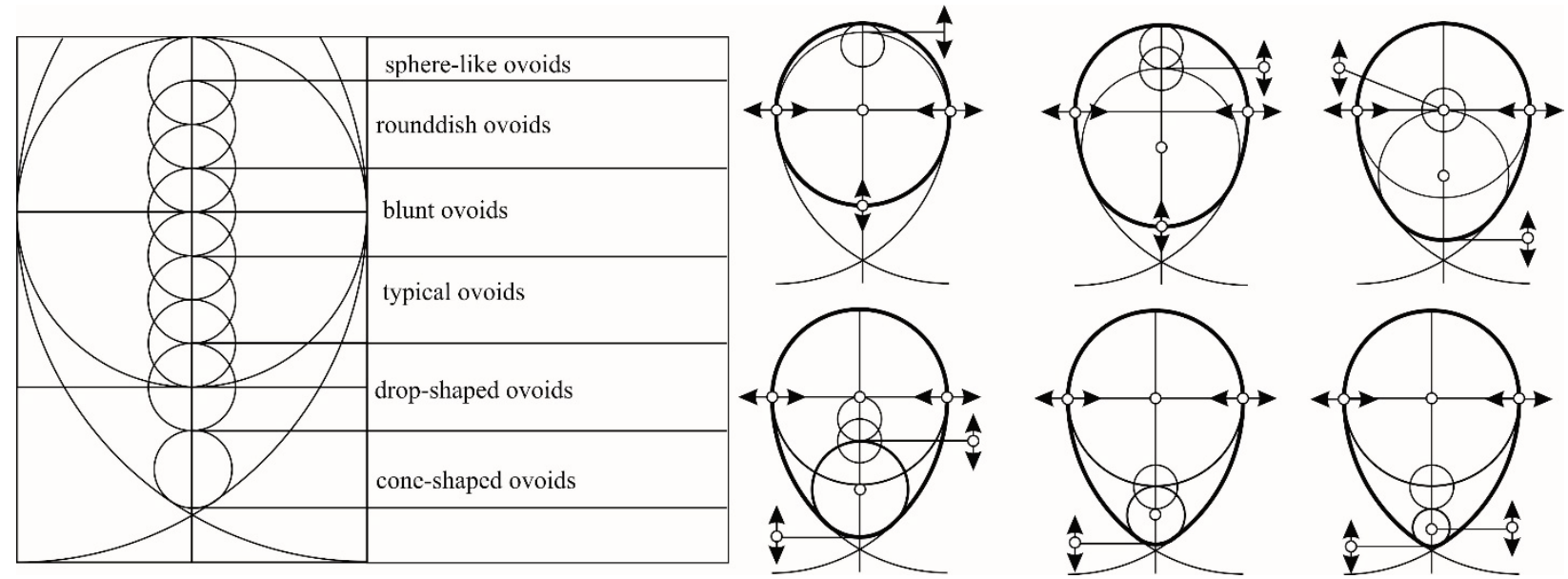

Fig. 3. Directions of movement of centers of radii of infundibular/cloacal arcs and types of ovoids

Further, we separated some more groups: short, shortened, normal, lengthened, and long; according to the sizes of cloacal arcs - large radius, middle radius, and small radius ovoids. As a result,we obtained 80 forms of real ovoids-standards, which occur between bird eggs (Mytiai \& Matsyura, 2017). Each of these has its own number, name, geometrical figure, equation of polynomial, and correlations of ovoid parameters. This set of ovoids thereof is sufficient to describe the specifics of any bird egg.

Among the birds' eggs, the number of real ovoids is $21.2 \%(\mathrm{n}=$ $16,490)$. They belong to 446 species $(65.5 \%)$ out of 10 orders. However, the maximum number of these forms is found among Passeriformes $(61.7 \%)$ and Charadriformes (20.0\%). Far fewer were determined in Falconiformes (6.3\%), Galliformes (4.0\%), Piciformes (1.8\%), and Gruiformes $(1.8 \%)$. The three other orders had about $1 \%$ of real ovoids.

The classic egg-shaped curve was also widely presented in mathematical sources (Köller, 2000; Nishiyama, 2007; Möller, 2009). Based on Cuadrad (2010), Petrović \& Obradović (2010), Iwamoto (2011), Caravaca (2015), and Yamamoto (2016), we included this curve with slight variations in the standard group called typical ovoids (Fig. 4).

Among the real ovoids $(n=3,490)$, the typical ovoids make up $36.1 \%$. Such eggs were found in 248 species of 7 bird orders. These are:
Passeriformes (62.9\%), Charadriformes (23.4\%), Galliformes (6.5\%), Gruiformes (2.4\%), Piciformes (2.4\%), Falconiformes (1.6\%), and Cuculiformes $(0.8 \%)$. The profile photos and patterns of the typical ovoids are shown in Figure 5. All other forms are the result of shortening or lengthening the ovoid, that should be caused by the increasing or decreasing the radii of the lateral and cloacal arcs. Mathematical curves of truncated ovoids proposed by various authors are shown in Figure 6 .

Among the above-mentioned, the most common are forms in which the radius of the cloacal zone is equal to half the difference between the length of the egg and the radius of the infundibular zone $(\mathrm{rc}=(\mathrm{L}-$ $0.5 \mathrm{D}) / 2$ ). In such forms, the edge of the cloacal ring bases on the center of main circle. These eggs are called obtuse medium-radius ovoids. Their profiles are presented in Figure 7.

Close to the above, there are ovoids in which the edge of the cloacal circle lies slightly above the centre of the base circle. These ovoids were initially proposed by Thom (1967). The similar curves were also suggested by other authors (Fig. 8). According to our classification, these forms are called obtuse large-radius (Fig. 9). Granvill \& Cadrin (Ferréol, 2016) proposed a group of oval curves, in which the cloacal circle is located just below the centre of the base circle (Fig. 10). 

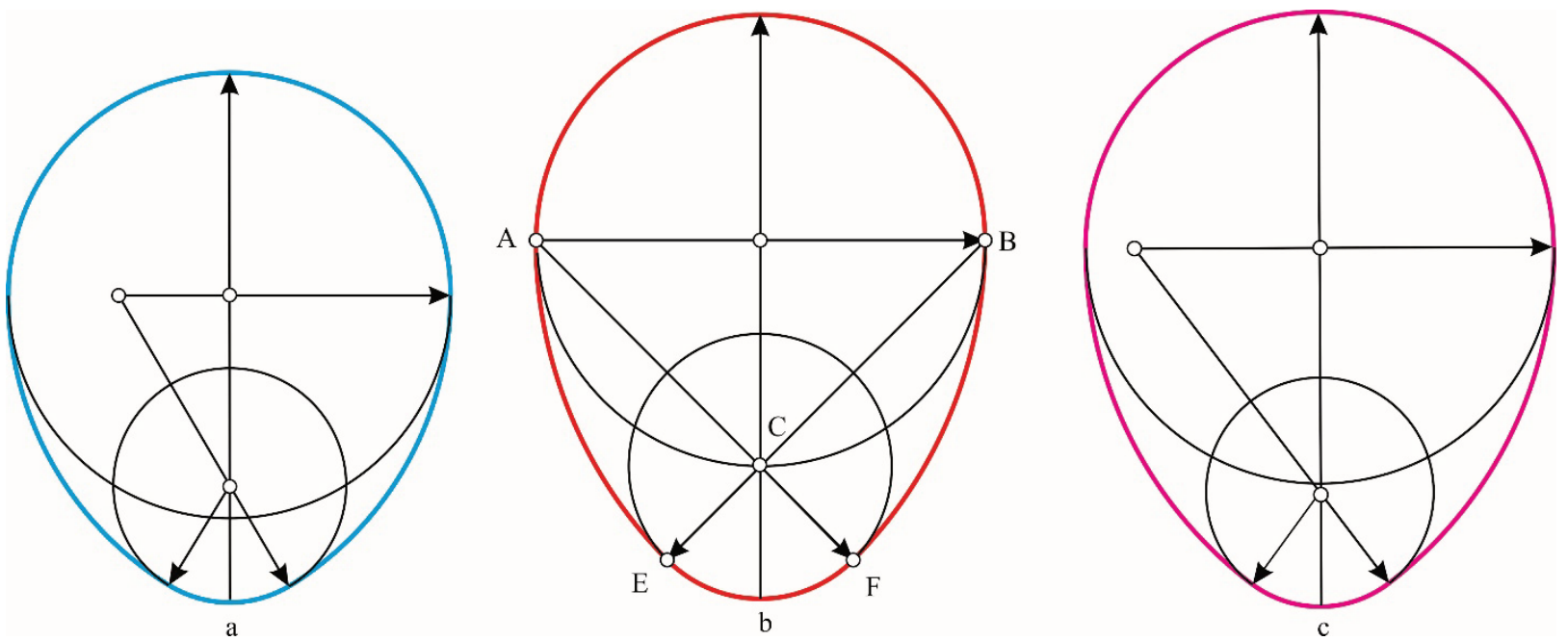

Fig. 4. Typical ovoids: $a$-Cundy \& Rollet ovoid (1989); $b$ - classic ovoid; $c$ - ovoid Sqrt 327 (Dixon, 1987)

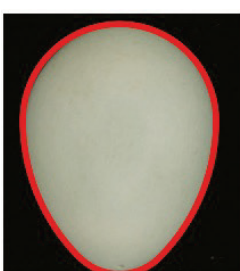

1
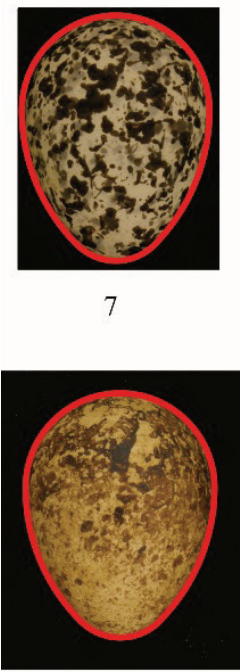

13

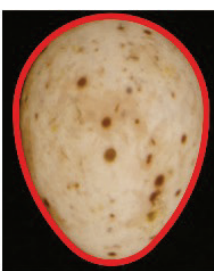

2
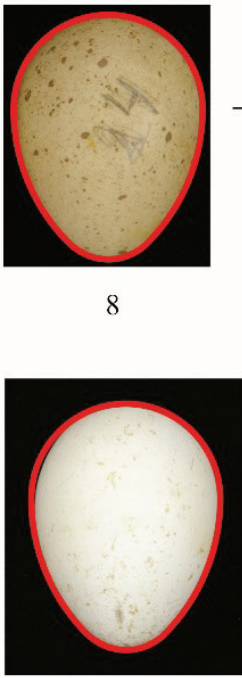

14

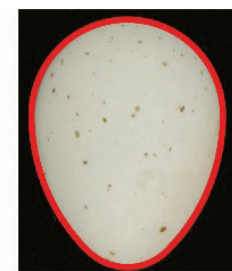

3

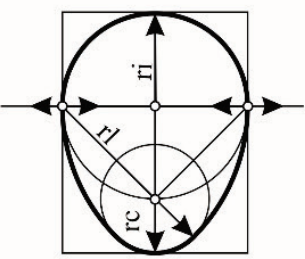

9

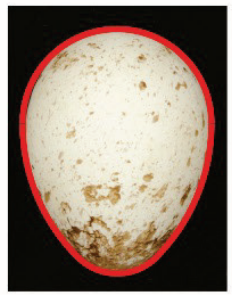

15

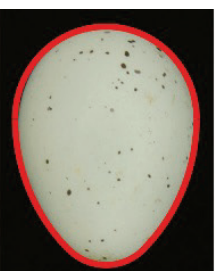

4

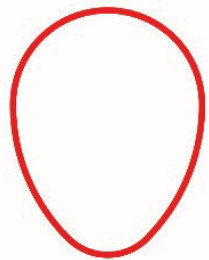

10

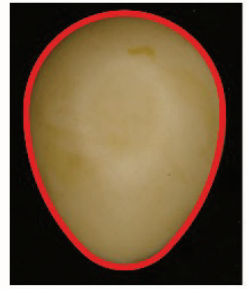

16

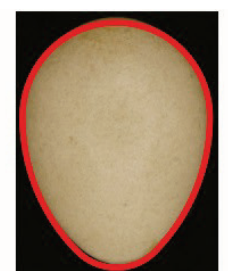

5

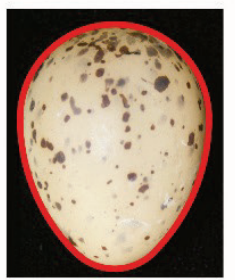

11

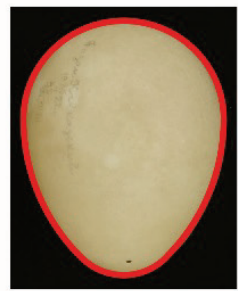

17

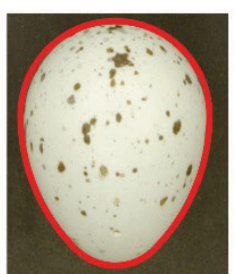

6

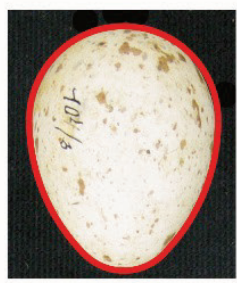

12

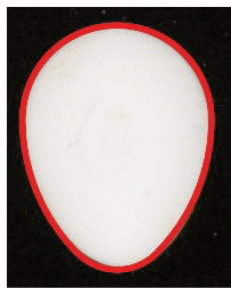

18

Fig. 5. Typical ovoids and their manifestation in the form of bird eggs: 1 - Saxicola rubetra; 2 - Sylvia atricapilla; 3 -Carpodacus erythrinus; 4-Turdus philomelos; 5 -Garrulus glandarius; 6-Corvus monedula; 7 -Glareola pratincola; 8 -Alectoris chukar; 9 - profile scheme of typical ovoids (circles - centrums of arcs, horizontally arrows - axis of centrum placement of lateral arcs); 10 - profile for comparison of real eggs; 11 -Larus canus; 12 -Crex crex; 13 - Falco tinnunculus; 14 -Milvus milvus; 15 -Buteo buteo; 16-Perdix perdix; 17 -Phasianus colchicus; 18 -Picus canus

These shapes are called obtuse small radius, their profiles are shown in Figure 11. In some forms the cloacal radius is equal to the fourth part of the length $(\mathrm{rc}=\mathrm{L} / 4)$; we also determined forms in which the ratio between the infundibular radius and cloacal is equal to the golden section (so-called golden eggs).

Among the real ovoids, obtuse ovoids make $29.5 \%$. Such eggs were found in 214 species from 8 orders of birds. These are: Passeriformes (69.2\%), Falconiformes (12.6\%), Charadriformes (7.9\%), Galliformes (4.7\%), Piciformes (2.4\%), Gruiformes ( $0.9 \%$ ), Cuculiformes ( $0.9 \%)$, and Coraciiformes $(0.5 \%)$. In the next group of forms, the center of cloacal curvature was positioned outside the base circle (Fig. 12). The averaged form has a cloacal radius equal to half the difference between length and diameter $\mathrm{rc}=(\mathrm{L}-\mathrm{D}) / 2$. These forms are called drop-shaped (Fig. 13).
Among the real ovoids, the drop-shaped form makes up $23.5 \%$. Such eggs were found in 132 species of 5 orders of birds. However, their main number is concentrated among two bird orders: Charadriformes (64.4\%) and Passeriformes (26.5\%). Far fewer are found in Galliformes (6.1\%), Gruiformes (2.3\%), and Sphenisciformes ( $0.8 \%)$.

The following group has forms that we call cone-shaped. These algebraic curves are proposed by Köller (2000), Nishiyama (2012), and Obramovic (2013) (Fig. 14). Among the real ovoids, these forms make up to $10.8 \%$ and were found in 51 Charadriidae species (Fig. 15). Thus, it is established that there is complete adequacy between the curves, mathematical calcultaions, and the natural bird egg curves. The same adequacy exists between the shape of eggs and architectural structures, sewage systems, and household objects. 
Thus, in the 1800s, the raw sewage in London swept through the streets and the Thames, creating unsanitary living conditions for the poor and a terrible smell for everyone (Webste \& Wagner, 1900). Bazalgette was the person who designed the sewage system to make the city a more attractive and survivable place to live.When new sewers were designed for London in the last half of the 1800s, the egg-shaped (or oval) sewers were determined to be the best cross-section for the larger "combined" sewers (this design is sometimes called "English" because of its association with London). The design was also used in Paris and for many early sewers in the United States (Fig. 16). Tubes of the ovoid form are still in use nowadays (Fig. 17). Technical drawings in these cases are also not the result of the study of bird eggs.
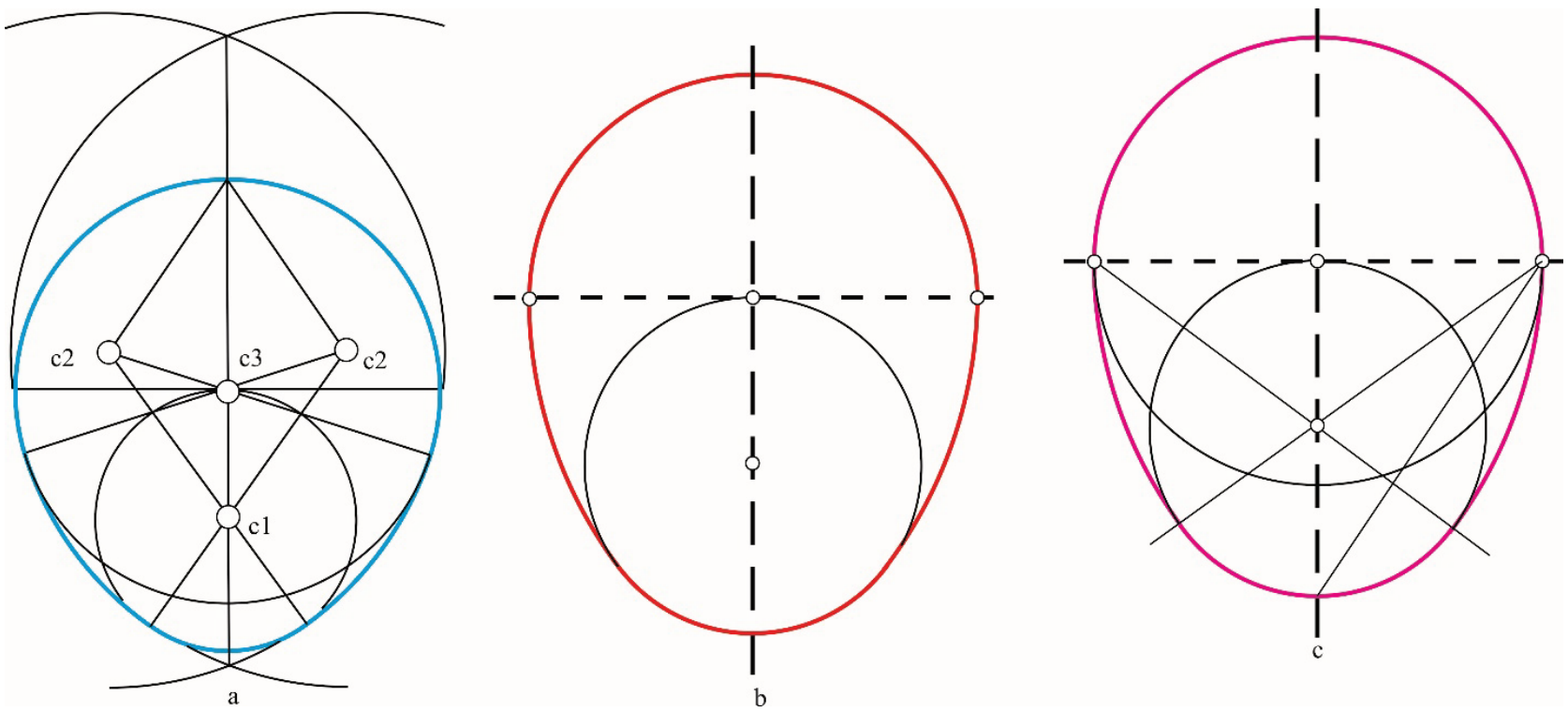

Fig. 6. Obtuse ovoids with an average radius: $a$ - Petrović, Obradović ovoid (2000), $b$ - Köllerovoid (2000), $c$-Caravaca ovoid (2015)
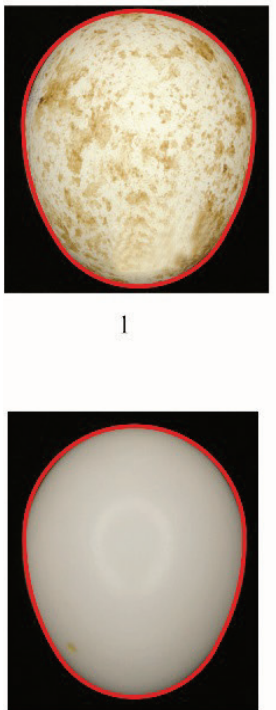

7

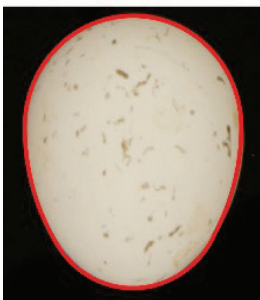

13

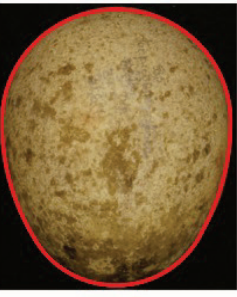

2
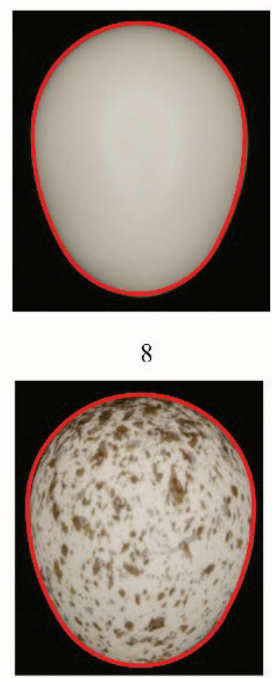

14
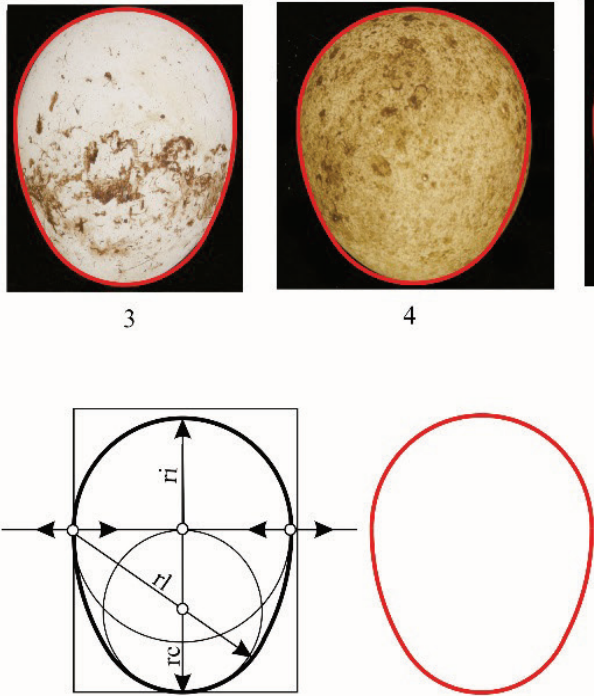

9

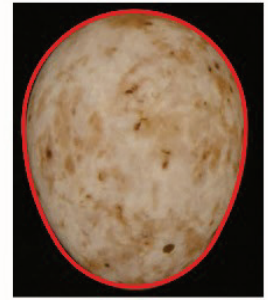

15

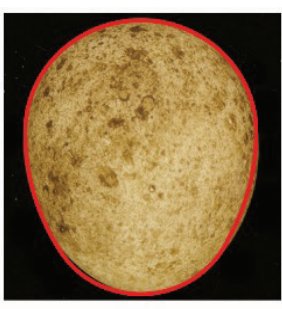

4

10

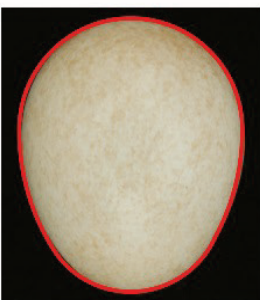

16
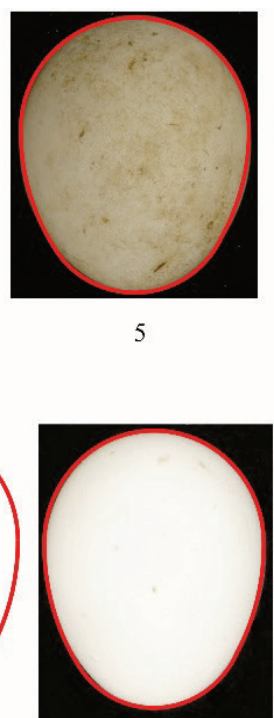

11

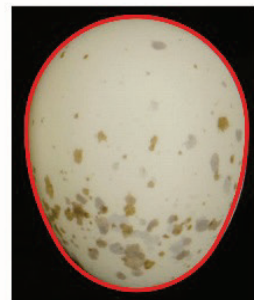

17
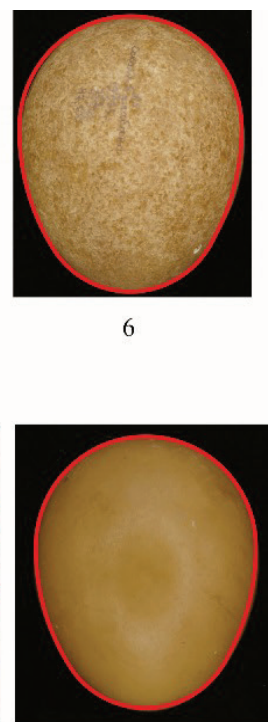

12

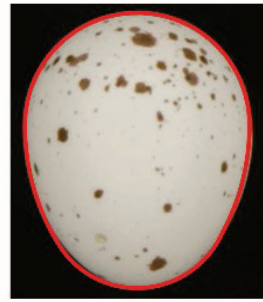

18

Fig. 7. Profiles of obtuse ovoids (medium radius) eggs: 1 -Hieraaetus pennatus; 2 - Falco tinnunculus; 3 - Jynx torquilla;

4-Coracias garrulus; 5 -Furnarius rufus; 6-Lanius collurio; 7 -Pernis apivorus; 8 -Perdix perdix; 9-profile scheme of typical ovoids (circles - centrums of arcs, horizontally arrows - axis of centrum placement of lateral arcs); 10 - control profile of real eggs; 11 - Buteo rufinus; 12 - Erithacus rubecula; 13 -Dendrocopos major; 14 - Phylloscopus sibilatrix; 15 -Certhia familiaris; 16 - Numida meleagris; 17 -Buteo buteo; 18 -Dendrocopos minor 


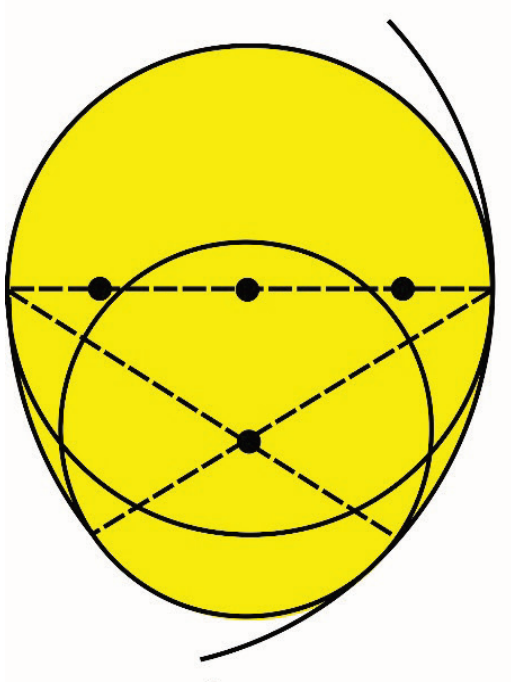

a

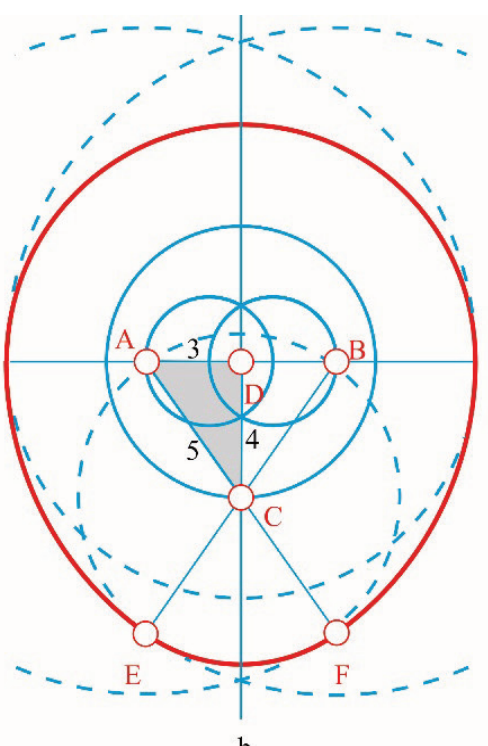

$\mathrm{b}$

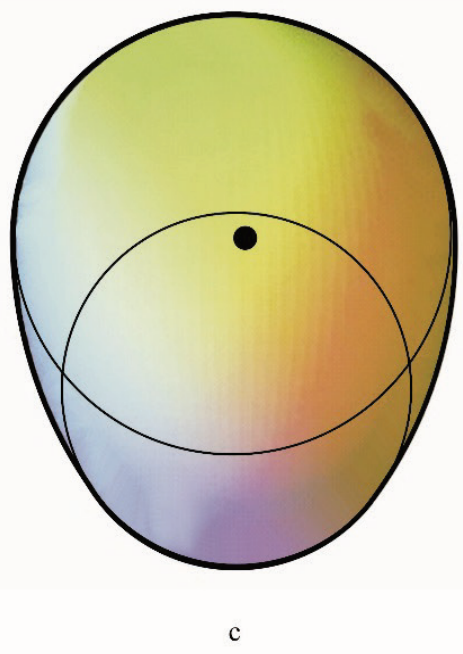

Fig. 8. Schemes of ovoids: $a$ - Thom ovoid (Thom, 1967); $b$ - ovoid 3, 4, 5 (Dixon, 1987); $c$ - ovoid A. de Quay (Ferréol, 2016)

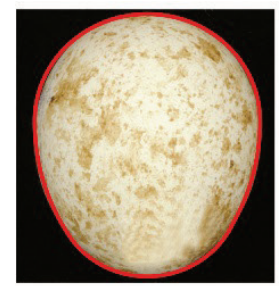

1

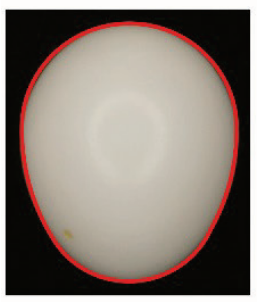

7

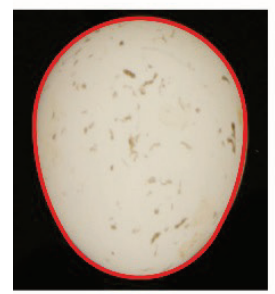

13
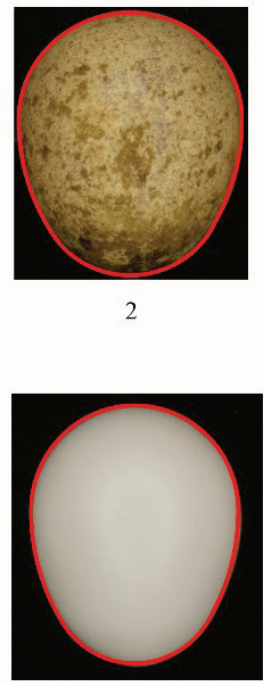

8

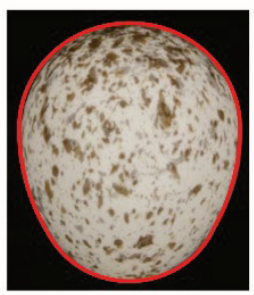

14

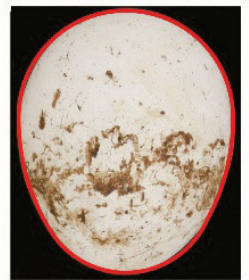

3

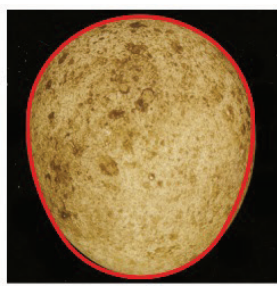

4
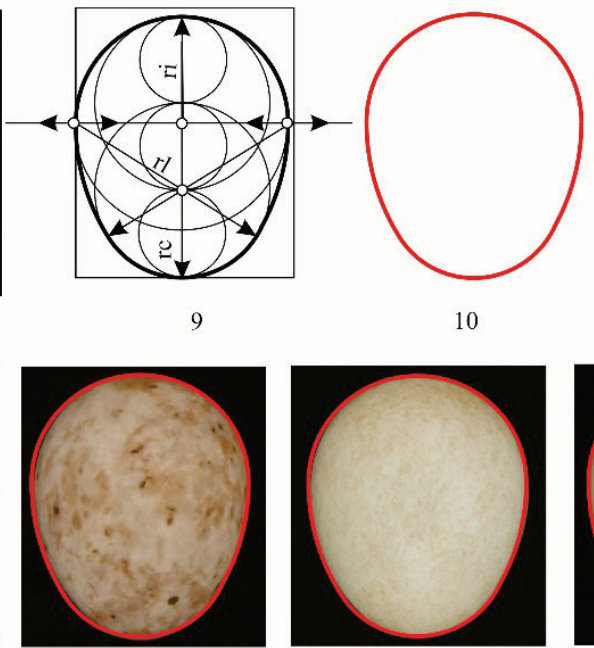

15
10

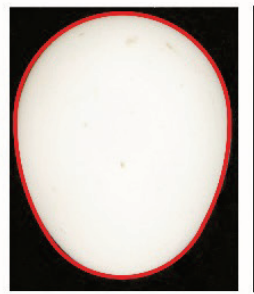

11

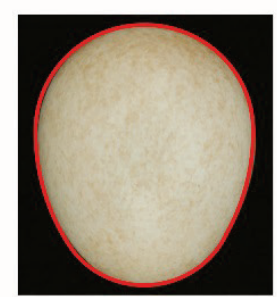

16

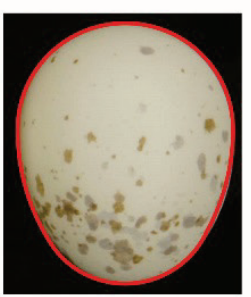

17

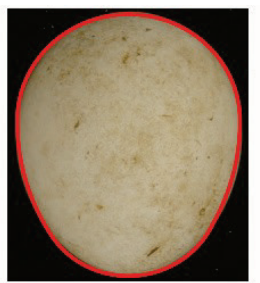

5

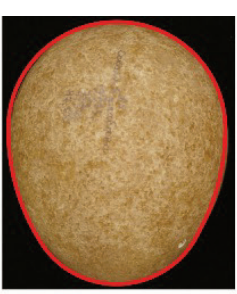

6

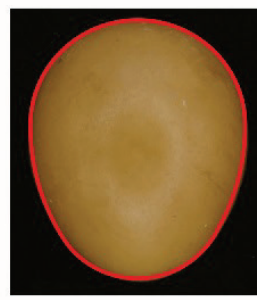

12

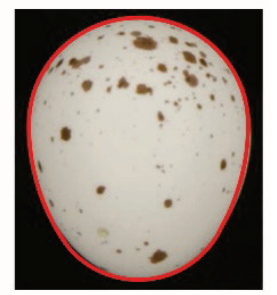

18

Fig. 9. Obtuse ovoids (large radius): 1 -Aquila pomarina; 2 - Falco tinnunculus; 3 -Milvus migrans; 4 - Falco vespertinus;

5 - Circus pygargus; 6 - Falco cherrug; 7 -Dendrocopos major; 8 -Jynx torquilla; 9 - profile scheme of obtuse ovoids (circles - centrums of arcs, horizontally arrows - axis of centrum placement of lateral arcs); 10 - control profile for comparison of real eggs; 11 - Picus canus; 12 - Phasianus colchicus; 13 - Panurus biarmicus; 14 - Phylloscopus sibilatrix; 15 - Sylvia atricapilla; 16 - Saxicola torquata; 17 - Lanius collurio; 18 -Phylloscopus collybita

\section{Discussion}

A much debated problem in current ornithology is the adequate description of eggs and the relationship between their shapes and incubation process under various environmental conditions, development strategies, directions of bird evolution and phylogeny. The egg, as a stage of ontogenesis, contains a significant amount of information that could be interpreted for predicting the incubation success and offspring quality for various bird species. However, many methods describing the shape of bird eggs do not properly consider the peculiarities of the ovoid shape, since the closed loop does not allow discovery of the egg's constituent parts.

In this regard, the composite ovoid method we use is more constructive, because here the egg profile is considered as a set of arcs of different radii, which smoothly merge into each other. The minimum number of them is three and this allows us to describe most eggs with acceptable accuracy. Besides, a large number of arcs set up a limited number of forms. As a result there is a piecewise continuous curve, whose rotation around its longitudinal axis forms a closed ovoid profile. Closing the contour leads to the appearance of two parameters: length 
(L) and diameter (D). The radii of the abovementioned arcs act as independent parameters. Each of them may arbitrarily change and lead to a non-linear change in $\mathrm{L}$ and $\mathrm{D}$ that gives rise to a great variety of forms. We are hardly ever able to describe these forms because of their nonlinearity.

Usage of digital photography and computer processing has significantly simplified the description of eggs by various polynomial equations (Todd \& Smart, 1984; Biggins et al., 2018) or by geometric morphometry (Deeming \& Ruta, 2014). These methods are accurate enough; however, they are less suitable for uncovering the morphological essence of the egg shape, since the coefficients of various equations reveal the functional relationship between the elements of the curve and the physical essence of the egg. Moreover, they are less suita- ble for the classification of egg forms. In this regard, our composite ovoid method is more constructive, which is evidenced by the system of standards of egg forms (Mytiai \& Matsyura, 2017).

Descriptive indices of egg shapes and their classification is quite common in modern ornithology. Biggins et al. (2018) carried out detailed and comprehensive analysis of this method. Three indices proposed by Preston (1968) - elongation, asymmetry, and bicone are still the most applicable. As regards the names and classification of forms, there are even more contradictions connected with indices. Until now, there are no generally accepted egg names and those used nowadays are not geometrically correct and informative (Petrović et al., 2014). The names of egg forms that are traditionally used in literature (spherical, oval, elliptical, bicone, pyriform) have many disadvantages.

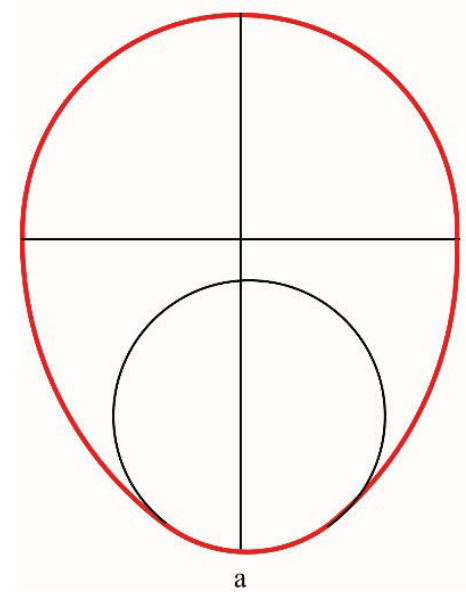

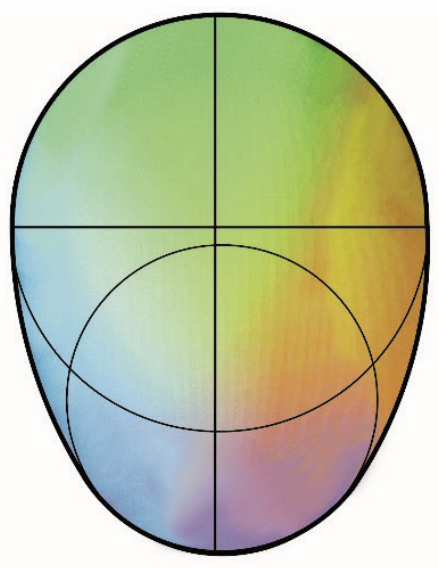

b

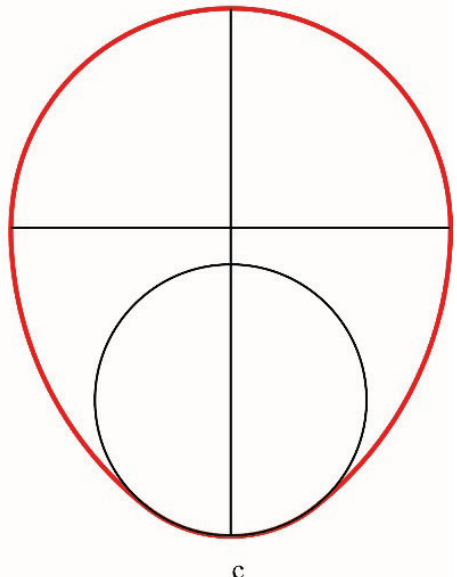

Fig. 10. Schemes of ovoids: $a$ - Granville ovoid (Ferréol, 2016); $b$ - Cardi novoid (Ferréol, 2016); $c$ - gold ovoid (Dixon, 1987)

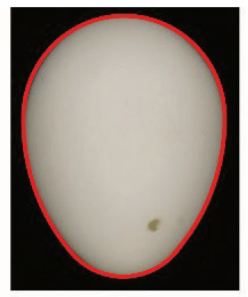

1

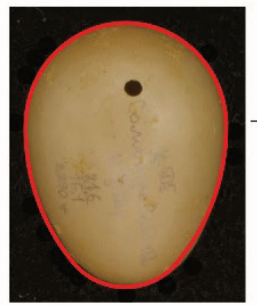

7

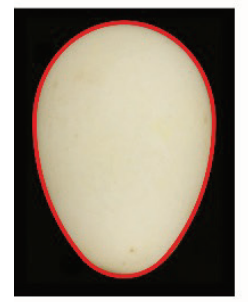

13

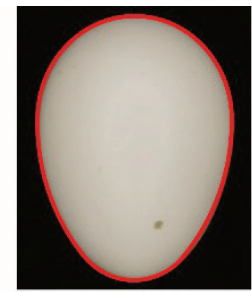

2

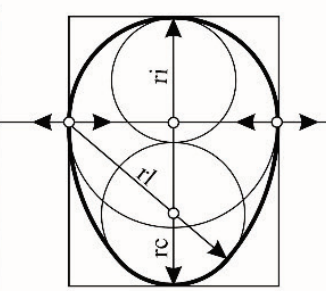

8

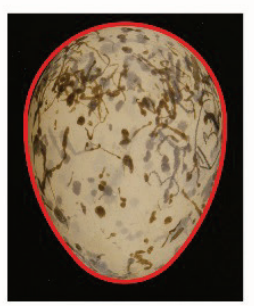

14

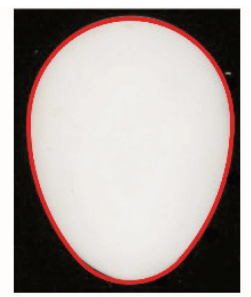

3

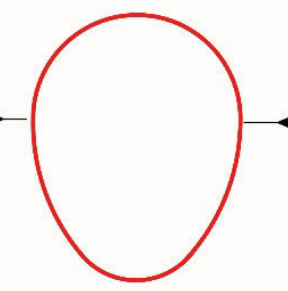

9

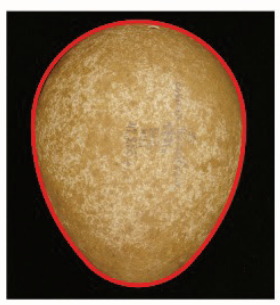

15

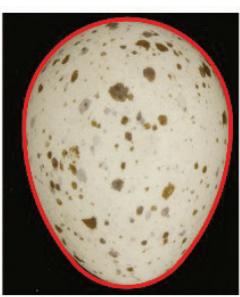

4

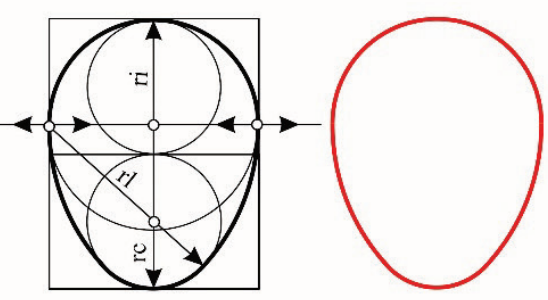

10

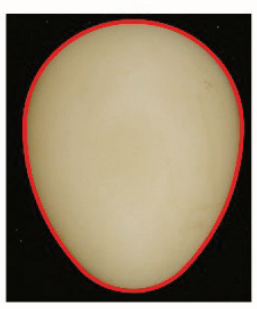

16

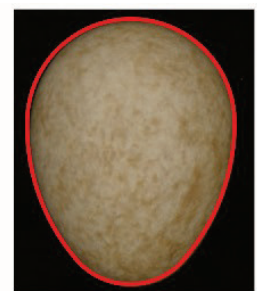

5
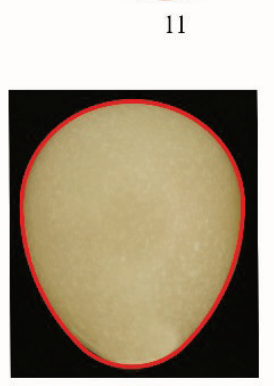

17

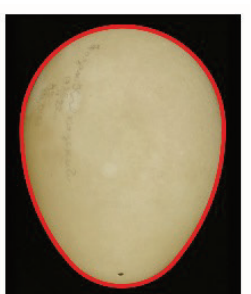

6

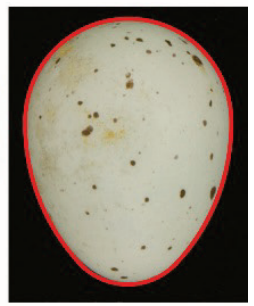

12

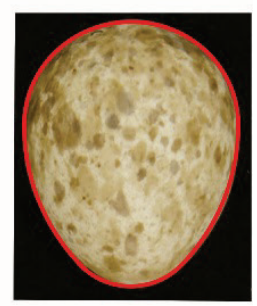

18

Fig. 11. Profiles of obtuse ovoids (small radius): 1 -Jynx torquilla; 2 -Dendrocopos major; 3 -Picus viridis; 4 -Corvus monedula;

5 -Motacilla flava; 6-Phasianus colchicus; 7-Luscinia luscinia; 8, 10-profile scheme of obtuse ovoids small radius (circles - centrums of arcs, horizontally arrows - axis of centrum placement of lateral arcs); 9, 11 - control profiles for comparison of real eggs; 12 - Turdus philomelos; 13 - Anas clypeata; 14 -Larus melanocephalus; 15 - Falco cherrug; 16 - Riparia riparia; 17 -Perdix perdix; 18 -Emberiza spodocephala 


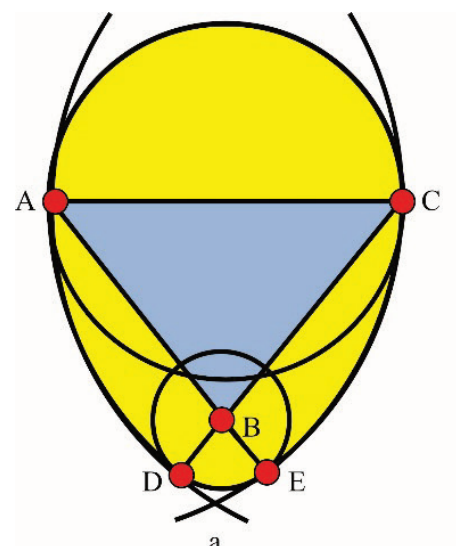

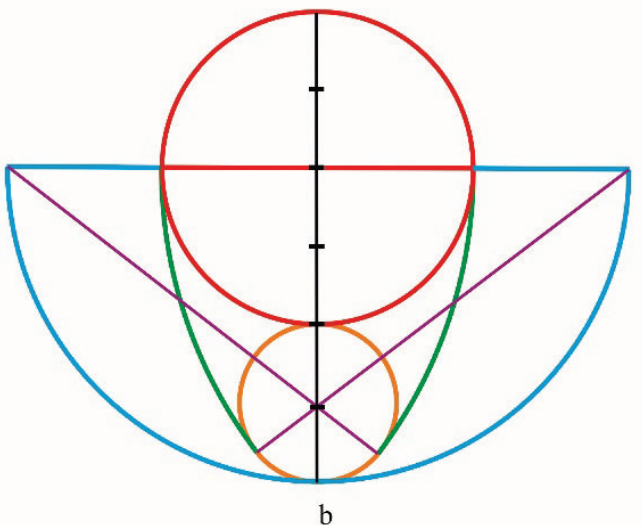

$\mathrm{b}$

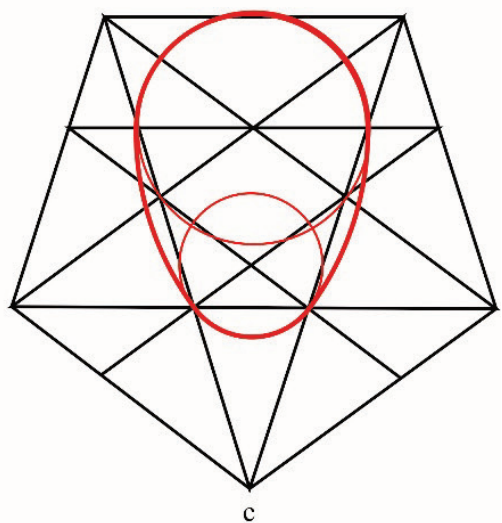

Fig. 12. Schemes of ovoids: $a$ - Moss ovoid; $b$-Antonio Castilla ovoid (Cuarado, 2010); $c$ - ovoid in pentagon (Ei-formen, 2000)

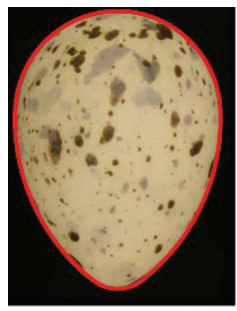

1

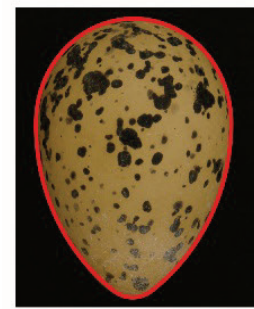

7

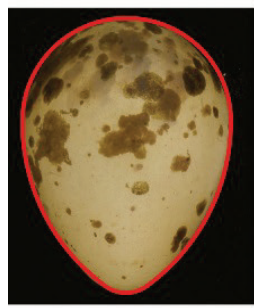

13
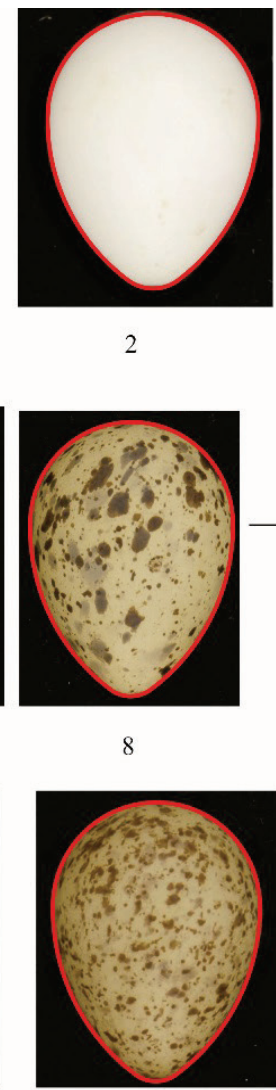

14
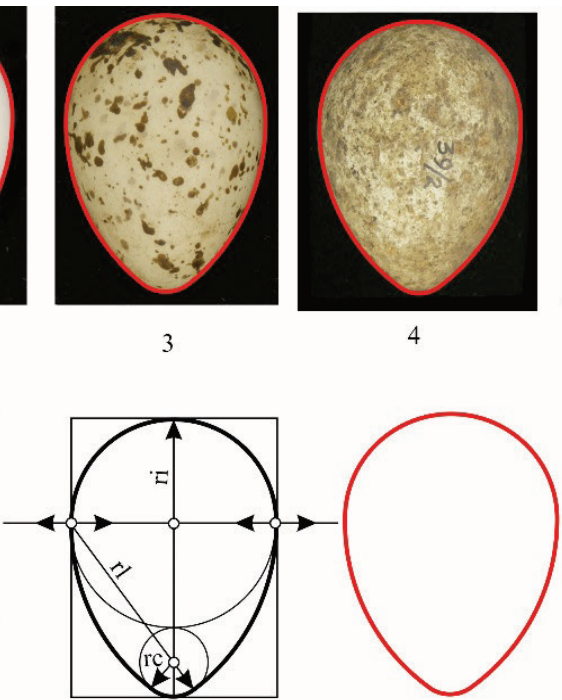

9

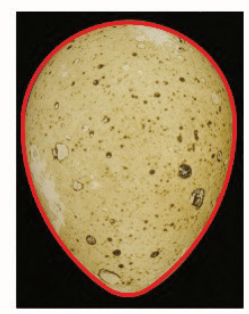

15

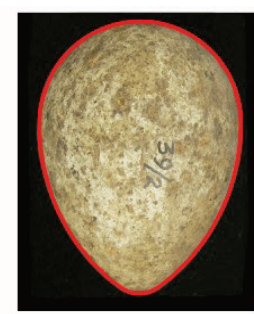

4

10

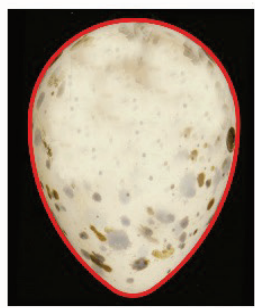

16

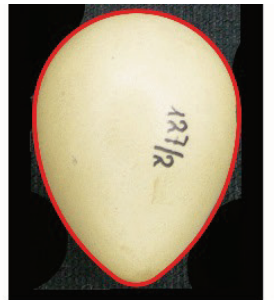

5

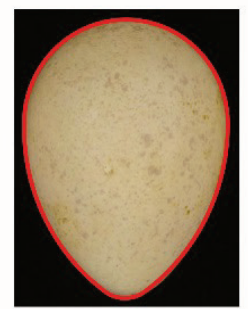

11

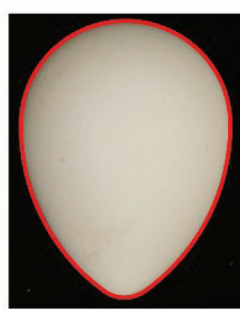

17
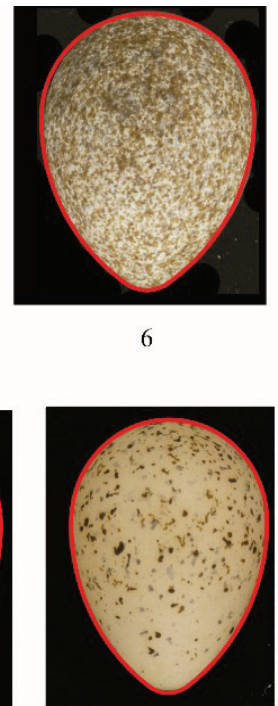

12

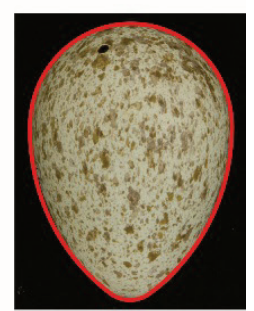

18

Fig. 13. Profiles of drop-shaped ovoids: 1 -Sterna albifrons; 2 -Riparia riparia; 3 -Chlidonias hybrida; 4 -Corvus corone; 5-Perdix perdix; 6 - Turnix tanki; 7 -Recurvirostra avosetta; 8 -Chlidonias hybrida; 9 - profile scheme of drop-shaped ovoids (circles - centrums of arcs, horizontally arrows - axis of centrum placement of lateral arcs); 10 - control profile for comparison of real eggs; 11 - ovoid Antonio Castilla; 12 - Gallinago gallinago; 13 -Calidris temminckii; 14 - Coturnix coturnix; 15 - Larus melanocephalus; 16-Lophortyx californicus; 17 - Alectoris chukar; 18 -Charadrius dubius

In most cases, the ovoid is called oval, but this is not entirely correct: oval is a symmetrical figure whereas ovoid is an asymmetric one. In fact, birds have no spherical eggs. The names bicone and pyriform are also uninformative. Recently, the number of works devoted to the quantitative and functional assessment of egg shape has increased. Biggins et al. (2018) suggested accurately quantifying the shape of birds' eggs. They carried out a fundamental analysis of common indices and considered the proper use of some three indices to characterize the forms. Anyway, they did not propose names and their classification of eggs. Since 2010, a significant number of articles have considered the relationship between egg form and its functional value. Stoddard et al. (2017) suggested the type of flight is a determining factor of egg shape; Deeming (2018) considered the inner composition of the egg as a core factor of egg shape; Birkhead et al. (2018) supposed that the pyriform egg shape can be adapted to breeding on sloping ledges. There still no names for the egg forms in these papers.

This situation virtually eliminates the possibility of comparing data from various authors. As we noted earlier (Mytiai \& Matsyura, 2017), the solution is possible by combining three aspects related to the egg form: name, geometric figure, and quantitative characteristic. We implemented this in our system of egg form standards. Unfortunately, we still do not have enough feedback from ornithologists. In this regard, here we give a more detailed description concerning the use of the standards' system.

As we suggested before, the standard is a numbered cell with assigned name, geometric shape, and quantitative indicators of the egg 
shape. We united the entire set of forms into a single system, and the egg figures are derived from the basic (classical, typical, and present) ovoid by topological transformation. Our classification is based on a comparison of the curvature sizes of egg zones.
We proposed to divide the egg forms into symmetric (ellipsoids and ovaloids) and asymmetric (typical ovoids and pseudoovoids) by equality of polar zones (infundural and cloacal). The radius of the infundibular zone in typical ovoid forms is equal to half the diameter.
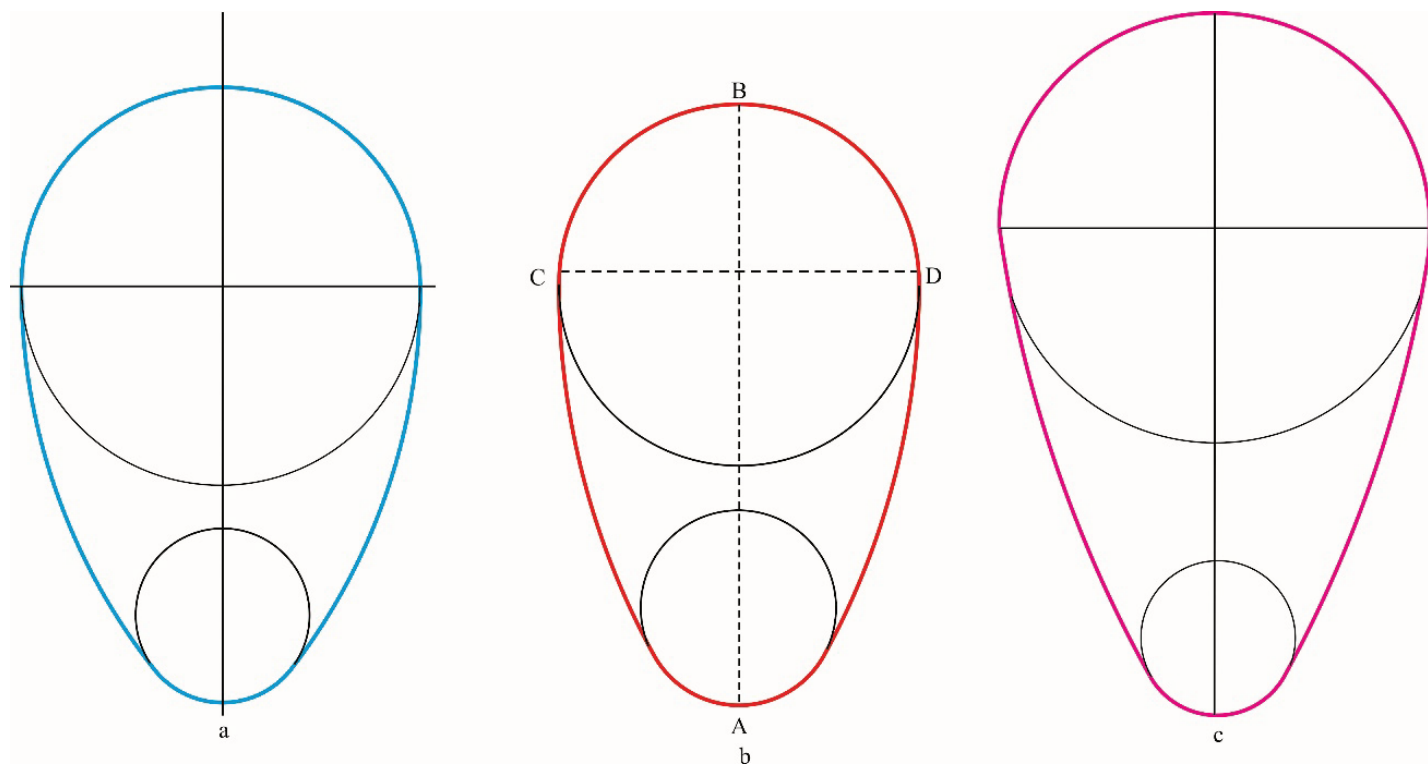

Fig. 14. Cone-shaped ovoids:

$a$ - Jacobs ovoid (Köller, 2000); $b$ - Nishiyama ovoid (2012); $c$ - Hugelschaffer's ovoid (Petrović \& Obradović, 2010)

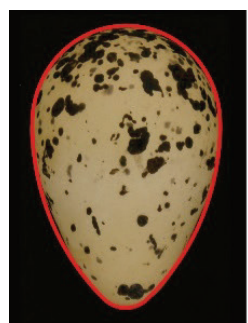

1

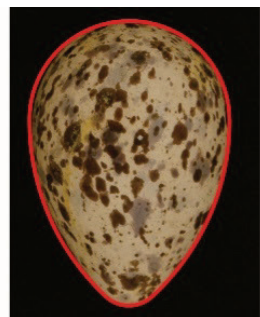

2

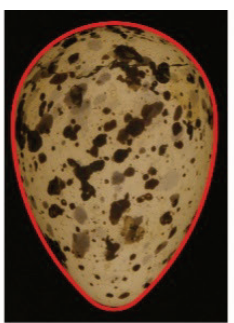

3

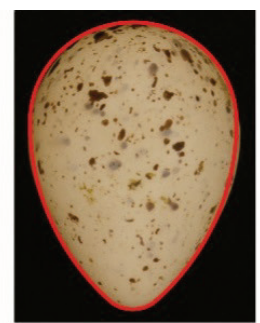

4

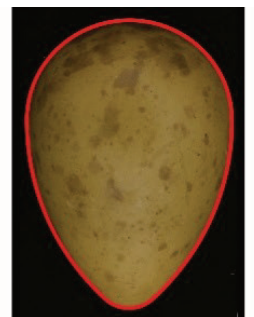

5

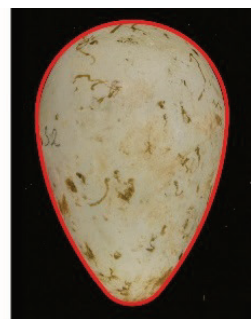

6

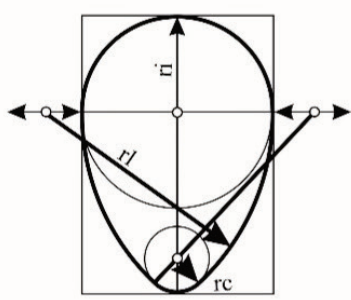

7

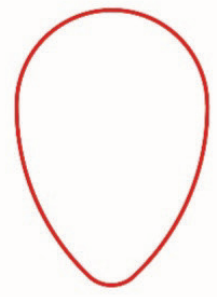

8

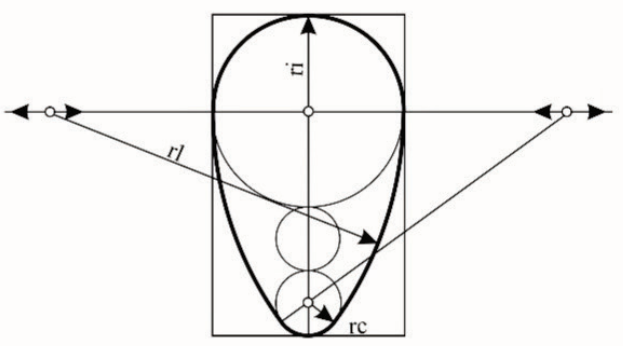

9

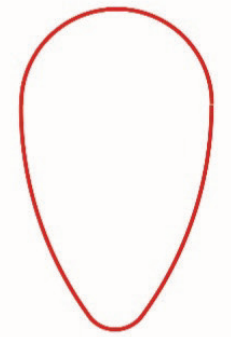

10

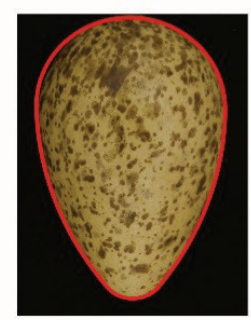

11

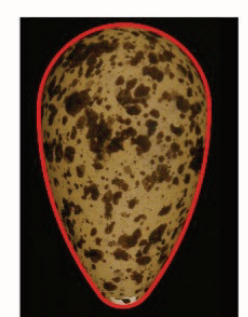

12

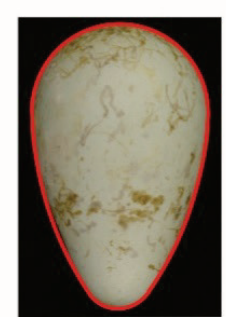

13

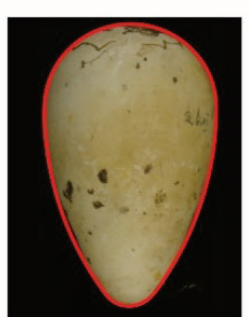

14

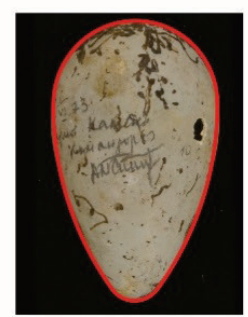

15

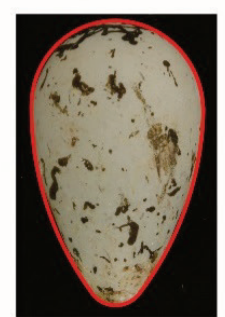

16

Fig. 15. Profiles of cone-shaped ovoids: 1 -Himantopus himantopus; 2 - Tringa nebularia; 3 -Tringa totanus; 4-Actitis hypoleucos; 5 - Limosa limosa; 6-Uria sp.; 7-10-profile scheme of cone-shaped ovoids (circles - centrums of arcs, horizontally arrows - axis of centrum placement of lateral arcs); 11 - Numenius arquata; 12 - Tringa totanus; 13-16-Uria sp. 

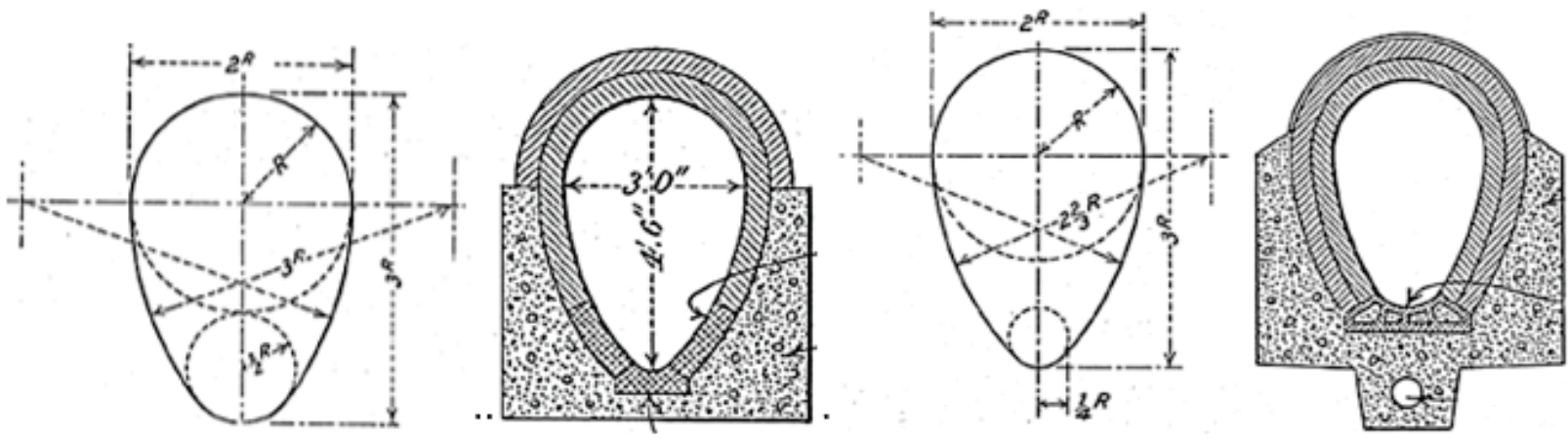

Fig. 16. Drawing of egg-shaped drain in the beginning of XX century (Webste \& Wagner, 1900)
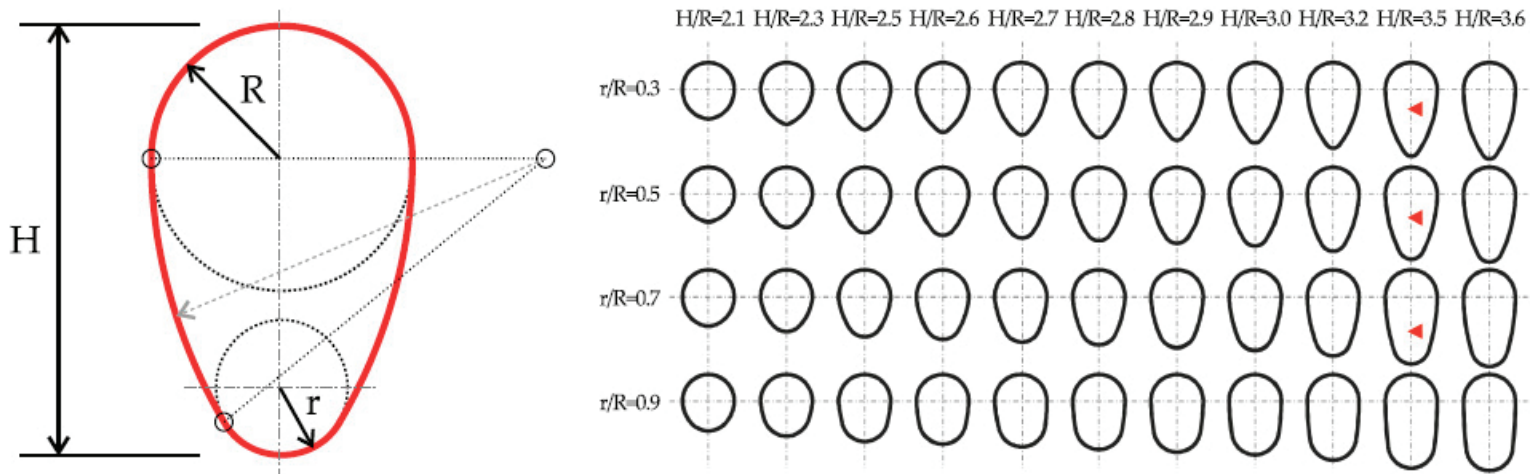

Fig. 17. Egg-shaped pipe drawings (Regueiro-Picallo et al., 2016)

We also suggested dividing the forms into sphere-like, roundish, obtuse, typical, drop-shaped and cone-shaped according to the location of the upper edge of the cloacal circle. We can divide these forms into short, short cut, normal, elongated, and long by the size of the lateral arcs. Finally, we assign the form names according to the size of the egg cloacal radius: large-radius, medium-radius, and small-radius. As a result, we obtain 80 standards, each of which has its own name, geometric shape, and quantitative parameters. For a basic ovoid, it looks like typi$\mathrm{cal}$ - normal - medium $(\mathrm{t}-\mathrm{n}-\mathrm{m}: 0.500-1.293-0.293)$. These numbers are indices of the infundibular (Ii) form.

We considered this method is relevant for the standards system since the topological transformation of the basic ovoid did not require any subjective input. The next step was to compare the figures obtained geometrically with the real forms of bird eggs, which led to good results as we presented above. We also identified the similarity of egg profiles with algebraic curves unrelated to ornithology. Finally, we found such coincidences in art, architecture, and even in profiles of water pipes (Petrovic et al., 2011). These facts proves the relevance of the ovoid form as a topologically transformed sphere and, therefore, the parameters of these transformations can be effectively used in the description of bird eggs and other objects of nature that have the same shape.

\section{Conclusions}

For centuries, mathematicians have developed a variety of egg-shaped curves based on algebraic equations. Architects and hydraulic engineers built various designs based on drawings. Artists have created various forms of eggs in the Faberge style. Not all of them were ornithologists studying the actual forms of eggs. On the other hand, birds have produced and incubated different forms of eggs that are unknown in mathematics, architecture, or even art. This circumstance shows that the ovoid form is the manifestation of the general morphogenesis law, which is revealed in mental and practical human activity, the form of planetary orbits, the form of bird and animal eggs, the egg-shaped body of animals, plants and their organs. All these aspects lead to the idea of a new look at the evolutionary process and the regularities of its manifestation. Moreover, the algorithm of scientific research also changes. Until now, the core pattern included raw data accumulation, its generalization and search for regularities. The new algorithm deals with a known ge- neral pattern and then we try to determine its manifestation in a particular natural object. From the very beginning, we know the parameters of the object and the possible ways of its variability. An excellent example is the Pythagorean figure Vesica piscis, from which all the egg forms are displayed.

As for the egg forms, it should be noted that the system of standards proposed by Mytiai \& Matsyura (2017) is a set of logical parameters that are interrelated and interchangeable. This system allows us to predict forms and their parameters to meet the optimal requirements of the incubation process.

\section{References}

Anderson, M. (1978). Optimal egg shape in waders. Ornis Fennica, 55, 105-109. Âvila, D. D. (2014). Aplicaciôn de las funciones elipticas de Fourier para la description de la forma de los liuevos de las aves. Revista de Biología Tropical Universidad de Costa Rica, 62(4), 1469-1480.

Baker, D. E. (2002). A geometric method for determining shape of bird eggs. The Auk, 119, 1179-1186.

Barta, Z., \& Székely, T. (1997). The optimal shape of avian eggs. Functional Ecology, 11, 656-662.

Biggins, J. D., Thompson, J. E., \& Birkhead, T. R. (2018). Accurately quantifying the shape of birds' eggs. Ecology and Evolution, 8, 9728-9738.

Birkhead, T. R., Jamie, E., Thompson, J. E., \& Montgomerie, R. (2018). The pyriform egg of the Common Murre (Uria aalge) is more stable on sloping surfaces. The Auk, 135(4), 1020-1032.

Bridge, E. S., Boughton, R. K., Aldredge, R. A., Harrison, T. E., Bowman, R., \& Schoech, S. J. (2007). Measuring egg size using digital photography: Testing Hoyt's method using Florida Scrub-Jay eggs. Journal of Field Ornithology, $78,109-116$.

Caravaca, J. B. (2015). Huevos, óvalos, y ovoides. Available from: http://pascuadeovalosyovoides.blogspot.com/2015/04.

Cuadrado, A. J. (2010). Curvas tecnicas y cyclicas. Available from: https://image.slidesharecdn.com/dibujotecnico-121119173546phpapp01/95/dibujotecnico.

Cundy, H., \& Rollett, A. (1989). Mathematical models. Third Edition. Stradbroke, Tarquin Pub.

Deeming, D. C. (2018). Effect of composition on shape of bird eggs. Journal of Avian Biology, 49(1), 1-7.

Deeming, D. C., \& Ruta, M. (2014). Egg shape changes at the theropod-bird transition and a morphometric study of amniote eggs. Royal Society Open Sciense, 1(3), 140311. 
Dixon, R. (1987). Mathographics. Dover Publications, New York.

Errős, L. (1983). A madártojások alakjának funkcionális szerepe. Aquila, 90, 159-185.

Ferréol, R. (2016). Blog. Ovoid. Available from: www.mathcurve.com/surfaces/ovoid/ovoid.shtml.

Frantsevich, L. (2010). Planimetry of the egg shape parameters. Available from: www.biometrica.tomsk.ru/planirus.htm (in Russian).

Führer-Nagy, G. (2002). Mathematical modeling of bird egg curves. Aquila, $107 / 108,67-73$

Ghyka, M. C. (1979). Esthétique des proportions dans la nature et dans les arts. Editorial Poseidon.

Heck, A. (2010). Mathematical brooding over an egg. Convergence.

Hreinsdóttir, F. (2010). Euclidian eggs. Blog: Dyna MAT. Available from: www.dm.unipi.it/georgiev/club/progectsDYNAMAT/ PUBLIC/D9_Ebook PDF_English/IS_EN_01_B_Euclidean_Eggs.pdf

Hutchinson, J. M. C. (2000). Three into two doesn't go: Two-dimensional models of bird eggs, snail shells and plant roots. Biological Journal of the Linnean Society, 70, 161-187.

Iwamoto T. (2011). Many shapes of bird's eggs. Available from: www.takayaiwamoto.com/Egg_Draw/Other_Birds_Egg.html.

Johnson, L. S., Leyhe, J. E., \& Werner, C. (2001). The shape of eggs in differentsize clutches of the House Wren (Troglodytes aedon). Canadian Journal of Zoology, 79, 1527-1531.

Köller, J. (2000). Mathematische Basteleien. Availble from: www.mathematische-basteleien.de/index.htm.

Kostin, Y. V. (1977). About methodology of oomorphological researches and unification of descriptions of oological material. In: Metodiki issledovaniya produktivnosti i struktury vidov ptits v predelakh ikh arealov [Methods of the study of the productivity and structure of bird species within their areals]. Vilnius (in Russian).

Mattas, M. (2001). Uraovani tvar u ptaaich vajec. Sylvia, 37, 17-25.

Mieszkalski, L. (2014). Method of mathematical modelling of the surface of the egg shell shape, egg yolk and air chamber of chicken eggs. Agricultural Engineering, 151(3), 93-104.

Möller, H. (2009). Das 2:3-Ei-ein praktikables Eimodell. Available from: www.math.uni-muenster.de/u/mollerh/data/ZweiDreiEi.pdf

Murray, C. M., Piller, K. R., \& Merchant, M. (2013). Salinity and egg shape variation: A geometric morphometric analysis. Journal of Herpetology, 47(1), 15-23.

Myand, R. (1988). Intrapopulational variability of bird eggs. Tallin, Valgu (in Russian).

Mytiai, I. S., \& Matsyura, A. V. (2017). Geometrical standards in shapes of avian eggs. Ukrainian Journal of Ecology, 7(3), 264-282.

Mytiai, I. S., \& Matsyura, A. V. (2018). Usage of the iterative photo-computing method in specifying of bird egg radiuses curvature. Ukrainian Journal of Ecology, 8(4), 195-204.

Mytiai, I. S., Levada, A. V., \& Tarusova, N. V. (2002). The symbol, the number of regularities is the logical components of the information field of the universe. Eniology, 3, 7-10 (in Russian).

Mytiai, I. S. (2008). Using modern technologies in researching of bird eggs. Zaporozhye National University Journal, Series Biology, 175-183 (in Russian).
Narushin, V. G. (2001). Shape geometry of the avian egg. Journal of Agriculture Engineering Research, 79, 441-448.

Nedomová, Š., \& Buchar, J. (2014). Goose eggshell geometry. Research in Agricuoture Engineering, 60, 100-106.

Nishiyama, Y. (2010). The mathematics of egg shape. Osaka University of Economics, Osaka. Available from: www.osaka-ue.ac.jp/zemi/nishiyama/math2010/ egg.pdf

Paganelli, C. V., Olszowka, A., \& Ar, A. (1974). The avian egg: Surface area, volume, and density. The Condor, 76, 319-325.

Petrović, M., Banjac, B., \& Malešević, B. (2014). The geometry of trifocal curves with applications in architecture, urban and spatial planning. Urban and Spatial Planning. Spatium, 32, 28-33.

Petrovic, M., Obradovic, M., \& Mijailovic, R. (2011). Suitability analysis of Hugelschaffer's egg curve application in architectural structures' geometry. Proceeding of International Conference on Engineering Graphics and Design, ICEGD JASSY 2011 - "Sustainable Eco Design".

Petrović, M., \& Obradović, M. (2010). The complement of the Hugelschaffer's construction of the egg curve. Proceedings Conference: 2nd International Conference for Geometry and Engineering Graphics "moNGeometrija 2010". Pp. 520-531.

Preston, F. W. (1953). The shapes of birds egg. The Auk, 70, 160-182.

Preston, F. W. (1968). The shapes of birds eggs: Mathematical aspects. The Auk, $85,454463$.

Regueiro-Picallo, M., Naves, J., Anta, J., Puertas, J., \& Suárez, J. (2016). Experimental and numerical analysis of egg-shaped sewer pipes flow performance. Universidade da Water, 8, 587.

Reid, W. S., Buckley, D. J., Hunt, J. R., \& Prices, K. A. (1974). Digital instrument for egg shape index measurement. Canadian Journal of Animal Science, 55, 87-92.

Rosin, P. L. (2004). On Serloi's construction of ovals. The Mathematical Intelligencer, 23, 58-69.

Shatkovska, O. V., Ghazali, M., Mytiai, I. S., \& Druz, N. (2018). Size and shape correlation of birds' pelvis and egg: Impact of developmental mode, habitat, and phylogeny. Journal of Morphology, 279(11), 1590-1602.

Stoddard, M. C., Yong, E. H., Akkaynak, D., Sheard, C., Tobias, J. A., \& Mahadevan, L. (2017). Avian egg shape: Form, function, and evolution. Science, 356, 1249-1254.

Thom, A. (1967). Megalithic sites in Britain. Clarendon Press, Oxford.

Todd, P. H., \& Smart, I. H. M. (1984). The shape of birds' eggs. Journal of Theoretical Biology, 106, 239-243.

Troscianko, J. (2014). A simple tool for calculating egg shape, volume and surface area from digital images. Ibis, 156(4), 874-878.

Webster, G. S., \& Wagner, S. N. (1900). History of the Pennsylvania Avenue Subway, Philadelphia, and sewer construction connected therewith. Transactions of the American Society of Civil Engineers, 44, 27.

Yamamoto, N. (2016). Equation of egg shaped curve of the actual egg is found. Available from: www.geocities.jp/nyjp07/index_egg_E.html

Zarraonandia, I. B. (2013). Blog: Dibujo Geométrico. Available from: https://ibiguri.wordpress.com/presentacion 